\title{
In vitro Evaluation of PHBV/PCL Blends for Bone Tissue Engineering
}

\author{
Amália Baptista-Perianes ${ }^{a}$, Sônia Maria Malmonge ${ }^{b} \mathbb{D}^{\mathbb{D}}$, Marcia Mayumi Omi Simbara $^{b}{ }^{\mathbb{D}}$, \\ Arnaldo Rodrigues Santos Junior ${ }^{a} \mathbb{D}$ \\ ${ }^{a}$ Centro de Ciências Naturais e Humanas (CCNH), Universidade Federal do ABC, São Bernardo do \\ Campo, SP, Brasil \\ ${ }^{b}$ Centro de Engenharia, Modelagem e Ciências Sociais Aplicadas, Universidade Federal do ABC, São \\ Bernardo do Campo, SP, Brasil
}

Received: May 15, 2019; Revised: August 31, 2019; Accepted: October 16, 2019

\begin{abstract}
The objective of this study was to evaluate Vero cells in in vitro biocompatibility tests with pure PHBV and PCL and 75/25 and 50/50 blends developed for bone tissue bioengineering in dense or porous forms. The biomaterials were characterized morphologically by scanning electron microscopy, (SEM) stereoscopic imaging (SI), and micrometer measurement. Cellular assay was made by MTT, morphological and cytochemistry analysis. The dense and porous scaffolds presented irregular surfaces. SEM allowed to observe details of the irregular surface throughout the dense samples and confirmed the absence of pores. It was found interconnected pores on porous samples. The porous samples were thicker than the dense samples. None of the polymers was considered toxic. Lower activity measured by MTT was observed for the 50/50 blends, suggesting a slower cell adhesion pattern. The cells were able to spread almost throughout the surface of the polymers, even into the pores. The dense and porous 50/50 samples were so brittle and difficult handling. Except for the 50/50 blends, the polymers were generally good substrates for the cells, were non-toxic, and exhibited the recommended morphological features. In addition, these biomaterials did not inhibit specific biological responses identified at the cytochemical level.
\end{abstract}

Keywords: poly(hydroxybutyrate-co-hydroxyvalerate), poly(e-caprolactone), tissue engineering, cell culture, bioreabsorbable polymers.

\section{Introduction}

The regenerative capacity of different tissues varies widely. Tissue repair is influenced by the type of tissue, severity of injury, and age of the individual. Medical interventions are often necessary for repair. Tissue engineering refers to the combination of cell biology and tissue methods with engineering and surgery ${ }^{1}$. Cells of the patient in conjunction with biomaterials developed as bioresorbable scaffolds can be used for this purpose creating a structure for repair or substitution of damaged tissue $\mathrm{e}^{1,2}$.

The most common bioresorbable scaffolds are synthetic aliphatic polyesters such as poly(glycolic acid) [PGA], poly(lactic acid) [PLA], and poly( $\varepsilon$-caprolactone) [PCL], which are widely used for tissue engineering techniques ${ }^{3}$. Other promising bioresorbable polymers are polyhydroxyalkanoates, polyesters produced by microorganisms via fermentation ${ }^{4}$. Particularly interesting polyhydroxyalkanoates are poly(3-hydroxybutyrate) (PHB), the copolymer of 3-hydroxybutyrate and 3-hydroxyvalerate (PHBV), poly(4-hydroxybutyrate) (P4HB), the copolymer of 3-hydroxybutyrate and 3-hydroxyhexanoate (PHBHHx), and poly(3-hydroxyoctanoate) (PHO). These compounds are used for different devices in biomedical applications ${ }^{5,6}$.
A very interesting property of PCL is its ductibility and propensity to form blends with a wide range of other polymers, thus compensating for deficiencies in some of their mechanical properties ${ }^{7,8}$. For example, $\mathrm{PHBV}$ is fragile and has a low rate of hydrolytic degradation due to its high degree of crystallinity. PCL is also high crystalline, however, the properties of PCL and PHBV may complement each other, forming a blend with characteristics that come adequate for use as scaffolds in tissue engineering ${ }^{6,9}$.

Promising results were obtained with the use of PLLA/ PHBV blends as substrates for the growth of fibroblasts ${ }^{10,11}$. In recent studies, dense PHBV/PCL blends have been evaluated regarding their possible use in the treatment of osteochondral defects $^{12}$. Mesenchymal stem cells cultured on dense PHBV/ PCL films exhibited a morphological pattern compatible with the phenotype of cells undergoing bone differentiation ${ }^{12}$. However, the utility of dense substrates is greatly limited. It has been postulated that porous materials implanted in vivo show better integration with the recipient tissue ${ }^{13}$. The pores facilitate vascularization and the diffusion of nutrients and gases ${ }^{14}$.

Based on experience related with fibroblast cell cultures $^{10,11}$ and the promising results obtained with the culture of mesenchymal stem cells on dense PHBV/ PCL blends ${ }^{12}$, this work proposes the evaluation of these polymers as porous materials in order to broaden their application in cell therapy and tissue engineering.

*e-mail: arnaldo.santos@ufabc.edu.br. 
The objective of this study was to culture fibroblastic cells on dense and porous PHBV and PCL pure and PHBV/PCL blends $(50 / 50$ and $75 / 25)$ for preliminary biocompatibility tests in order to determine their utility as biomaterials for bone tissue repair.

\section{Material and Methods}

\subsection{Preparation of the dense and porous membranes of PHBV, PCL and its blends}

Materials: PHBV (12\% wt 403121-100G) and PCL (440744-250G, Mn 70000-90000) were purchased from Sigma Aldrich. Chloroform was purchased from Synth, sodium chloride $(\mathrm{NaCl})$ was purchased from Vetec Química and ethanol $(99,8 \%)$ was purchased from Isofar. Preparation of dense and porous scaffolds: Solvent casting technique was used to produce dense membranes of PHBV, PCL and the two blends (PHBV:PCL 50:50 and 75:25). The polymers were individually dissolved in chloroform in a proportion of $5 \%$ w/v using a magnetic agitator. The solutions were cast into Petri dishes and left for solvent evaporation in the hood with the exhaustion turned off. To produce the porous scaffolds (with the same compositions), $\mathrm{NaCl}$ crystals (with diameters ranging from $180 \mu \mathrm{m}$ to $300 \mu \mathrm{m}$ ) were added to each solution $(100 \% \mathrm{w} / \mathrm{v}, 1 \mathrm{~g}$ of $\mathrm{NaCl}$ for each $\mathrm{ml}$ of polymer solution), which were also cast into Petri dishes. After solvent evaporation, the scaffolds remained immersed in distilled water for 48 hours to leach out the salt. Finally, the scaffolds were washed with ethanol for 24 hours and left to air dry. The tests adopted in this study are recommended by the ASTM F813-83 ${ }^{15}$ for the evaluation of biomaterials according to international standards ${ }^{16}$. The polymers were disinfected in $70 \%$ alcohol (16h at room temperature) and medium 199 (Lonza) without fetal bovine serum (FBS) (incubator at $37^{\circ} \mathrm{C}$ for $24 \mathrm{~h}$ ).

\subsection{Morphological characterization of the membranes.}

The membranes of pure polymers and blends were characterized morphologically by scanning electron microscopy (SEM), stereoscopic imaging, and their thickness were determined by micrometer measurement. The samples were directly examined under a compact scanning electron microscope (JSM-6010LA, JEOL) at the Multiuser Experimental Center (CEM) of UFABC. Photographs were taken from all samples with a digital camera coupled to a stereoscope (Physis, model SZ40) at 1.0X, 1.5X, 2.0X, 3.0X, and 4.0X magnification. The thickness of the blends and pure polymers membranes was measured with a digital external micrometer ( 0 to $25 \mu \mathrm{m}$, Digimess) at five different points in each material studied. The measurements were made in triplicate. For pore diameter determination, Image J was used. Porosity could also be determined by the method described by Leblon et $\mathrm{al}^{17}$, using the following equation: $\mathrm{p}(\%)=\left(\mathrm{p}_{\mathrm{p}}-\mathrm{p}_{\mathrm{s}}\right) / \mathrm{p}_{\mathrm{s}} \times 100$, where: $\rho_{\mathrm{p}}=$ polymer density not porous and $\rho_{\mathrm{s}}=$ the density of the porous polymer.

\subsection{Cell culture}

Vero cells, a fibroblast cell line established from kidney cells of the African green monkey (Cercopithecus aethiops) obtained from the Adolfo Lutz Institute, São Paulo, Brazil, were used. The cells were cultured in medium 199 (Lonza Group Ltd., USA) with 10\% FBS (Nutricell Nutrientes Celulares, Campinas, $\mathrm{SP}, \mathrm{Brazil}$ ) at $37^{\circ} \mathrm{C}$ in an oven with $5 \% \mathrm{CO}_{2}$. The medium was always changed in the case of acidification and subcultures were prepared twice a week. All assays were made among cell passage 147 to 151 . Vero cells are recommended for studies of cytotoxicity and cell-cell interactions on biomaterials ${ }^{16,18}$.

\subsection{MTT assays}

Two MTT (3-(4,5-dimethylthiazol-2-yl)-2,5-diphenyl tetrazolium bromide) assays were carried out to evaluate Vero cells cultured on the dense and porous materials. Samples of each polymer $(n=5)$ were placed in 96-well plates (Corning Costar Corporation, Cambridge, MA, USA). Samples were cut to fill all well space ( $5 \mathrm{~mm}$ diameter). Next, $200 \mu \mathrm{L}$ of a cell suspension $\left(2 \times 10^{5}\right.$ cells/well $)$ were inoculated onto the materials. The plates were incubated at $37^{\circ} \mathrm{C}$ with $5 \% \mathrm{CO}_{2}$ for $24 \mathrm{~h}$ in the first experiment and for $48 \mathrm{~h}$ in the second experiment. After this period, $10 \mu \mathrm{LMTT}$ was added to each well. The plates were incubated at $37^{\circ} \mathrm{C}$ with $5 \% \mathrm{CO}_{2}$ for $4 \mathrm{~h}$ in the dark. One hundred microliter of $10 \%$ sodium dodecyl sulfate (SDS) was then added to each well for cell membrane rupture. Absorbance was read after $12 \mathrm{~h}$ in a DNM 9602 Microplate Reader (Beijing Perlong New Technology Co., Ltd.) at a wavelength of $570 \mathrm{~nm}$. Only medium 199 without serum and the same reagents as described above were added to the wells without cells or material (blank). Wells containing only the materials without cell inoculation served as control of the reaction. The plate itself (cells without material) was used as positive control and wells containing cells and $70 \%$ alcohol to induce a decline in viability were used as negative control. The results were analyzed statistically by oneway ANOVA, followed by Tukey HSD multiple comparison test, adopting a level of significance of $5 \%$.

\subsection{Morphological analysis}

Morphological analysis of cells submitted to cytotoxicity testing using extract and direct contact tests ${ }^{16}$ were performed. The extracts were obtained by incubating the different materials $(0.2 \mathrm{~g} / \mathrm{mL})$ in medium containing $10 \% \mathrm{FBS}$ at $37^{\circ} \mathrm{C}$ for $48 \mathrm{~h}$ without shaking. The extract was then collected to evaluate the possible effect of soluble substances released by the different materials. The extracts obtained were used for cell culture. The cells were inoculated at a concentration of $2 \mathrm{x}$ $10^{5}$ cells $/ \mathrm{mL}$ in 24 -well plates with medium 199 plus $10 \%$ FBS at $37^{\circ} \mathrm{C}$. After $24 \mathrm{~h}$, the culture medium was replaced with the extracts and respective controls and the plates were incubated under the same conditions for an additional $24 \mathrm{~h}$. The samples were fixed in $10 \%$ formalin (in $0.1 \mathrm{M}$ PBS at $\mathrm{pH}$ 7.2) in the culture plate and washed twice with distilled water. The cells were stained with crystal violet. 
For the direct contact test, the polymers were cut to fill all well space (14 mm diameter) and placed in a 24-well plate. Vero cells were inoculated at a concentration of about $2 \mathrm{x}$ $10^{5}$ cells/well $(1.5 \mathrm{~mL})$ onto the pure polymers and PHBV/ PCL blends (dense and porous samples). The plate itself was used as the negative control. The cells were incubated in medium 199 plus $10 \% \mathrm{FBS}$ at $37^{\circ} \mathrm{C}$ with $5 \% \mathrm{CO}_{2}$. After 5 days, the medium was removed from the wells and the samples were fixed in $10 \%$ formalin (in $0.1 \mathrm{M}$ PBS at $\mathrm{pH} 7.2$ ) in the culture plate and washed twice with distilled water. The cells were stained with crystal violet.

\subsection{Cytochemical analysis}

The cells that grew in direct contact with the different substrates as described above were stained with toluidine blue (TB) at pH 4.0 (identification of DNA, RNA and glycosaminoglycans - GAGs), TB at $\mathrm{pH} 2.5$ (identification of GAGs only), xylidine ponceau (XP) at pH 2.5 (total proteins), picrosirius hematoxylin ( $\mathrm{PH}$; identification of collagen), Verhoeff's stain (elastic fibers), periodic acid Schiff (PHS; identification of neutral sugars and glycoproteins), and silver (reticular fibers) ${ }^{18,19}$. The samples were analyzed with a light microscope (Nikon, model 80i) under a 20X objective. The images were photographed with a Nikon Digital Sight camera (DS-Ri1) coupled to the microscope and captured with the NIS-Elements software. In view of the irregularities of the substrates, 4 to 12 images of the same field were obtained for each material and photographed under a $4 \mathrm{X}$ objective at intervals of $0.5 \mu \mathrm{m}$. For the $40 \mathrm{X}$ objective, the images were captured at intervals of $0.2 \mu \mathrm{m}$. All images captured were merged in the Combine ZP software and processed with the Axio Vision and Adobe Photoshop programs. Negative controls (wells without material) were also stained with $\mathrm{TB}$ and crystal violet and were analyzed under an Olympus IX71 light microscope at 4X and 40X magnification. The images were obtained with a Lumenera camera coupled to the microscope and the Infinity Analyze software. Cells that grew around the polymers were also photographed using this microscope.

\section{Results}

\subsection{Morphological characterization of the PHBV, PCL and blends}

The stereoscopic images of the samples (Figure 1) showed that the dense and porous membranes presented irregular surfaces, which can even be seen in details by SEM analysis (Figure 2). Table 1 shows the values of thickness for dense and porous membranes obtained with PHBV, PCL and their blends. In general, the porous samples were thicker than the dense samples.
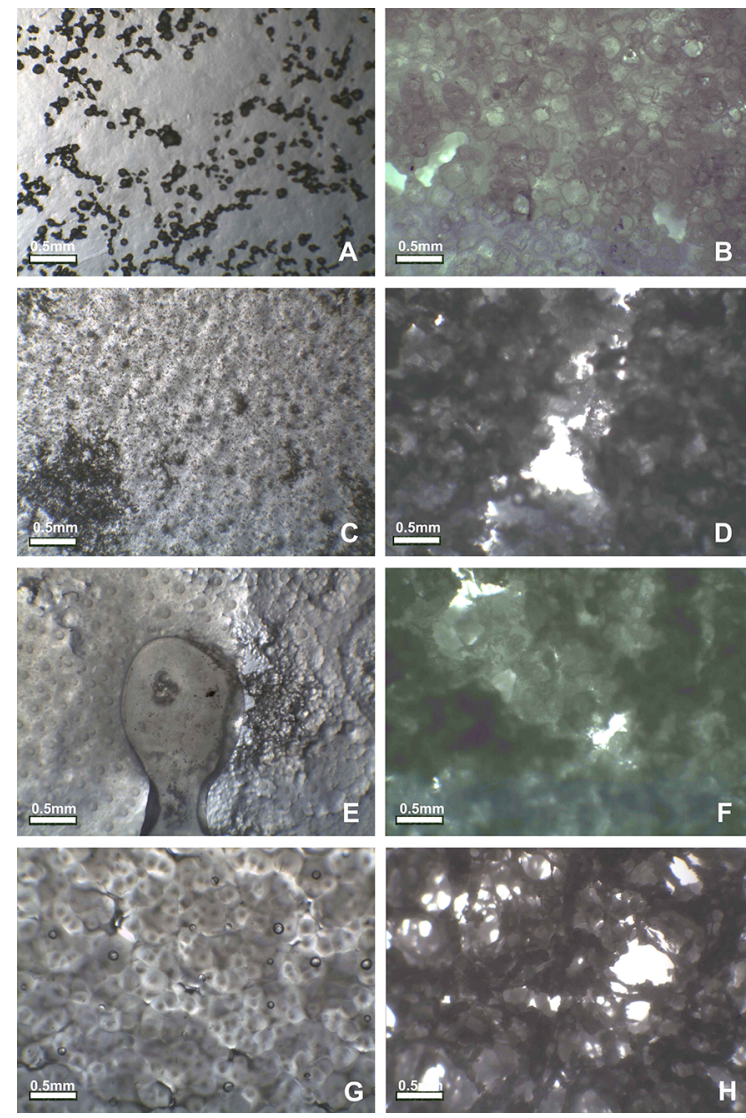

Figure 1. Light microscopy characterization of the samples studied A) Dense PHBV, B) porous PHBV, C) dense PHBV/PCL (75/25), D) porous PHBV/PCL (75/25), E) dense PHBV/PCL (50/50), D) porous PHBV/PCL (50/50), G) dense PCL, H) porous PCL. Scale bar $=0.5 \mathrm{~mm}$ for all images.

Table 1. Thickness $(\mathrm{mm})$ of the pure polymers and of the PHBV/PCL blends.

\begin{tabular}{lcc}
\hline Sample & $\begin{array}{c}\text { Mean } \\
(\mathbf{m m})\end{array}$ & $\begin{array}{c}\text { Standard } \\
\text { deviation }\end{array}$ \\
\hline Dense PHBV & 0.166 & 0.004 \\
Dense PHBV/PCL (75/25) & 0.178 & 0.034 \\
Dense PHBV/PCL (50/50) & 0.211 & 0.016 \\
Dense PCL & 0.163 & 0.007 \\
Porous PHBV & 1.196 & 0.083 \\
Porous PHBV/PCL (75/25) & 0.188 & 0.034 \\
Porous PHBV/PCL (50/50) & 1.360 & 0.107 \\
Porous PCL & 0.527 & 0.055 \\
\hline
\end{tabular}

SEM analysis allowed to observe details of the irregular surface throughout the dense samples and confirmed the absence of pores in these samples. Dense PHBV and the 50/50 blend showed no apparent porosity, but the irregularities in the 75/25 blend and pure PCL resembled pores (Figure 2). 

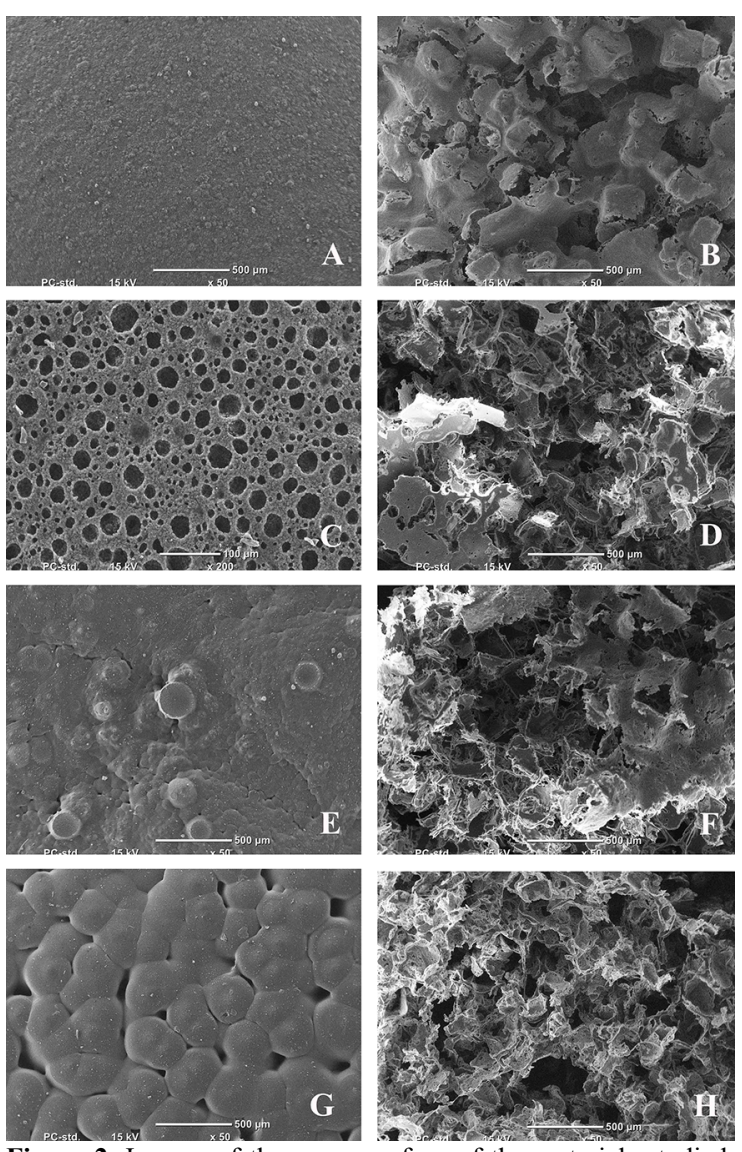

Figure 2. Images of the upper surface of the materials studied. A) Dense PHBV, B) porous PHBV, C) dense PHBV/PCL (75/25), D) porous PHBV/PCL (75/25), E) dense PHBV/PCL (50/50), D) porous PHBV/PCL $(50 / 50), \mathrm{G})$ dense PCL, H) porous PCL. Scale bar $=500 \mu \mathrm{m}$.

In the porous samples, pores are distributed no homogeneously and present different diameters (Figure 2). All samples showed surface irregularities, whose appearance varied from composition to composition. For the pore diameter measurement, the following results were found: 280 $\pm 100 \mu \mathrm{m}$ for PHBV; $245 \pm 130 \mu \mathrm{m}$ for 75:25 blend; $230 \pm$ $91 \mu \mathrm{m}$ for $50: 50$ blend and $242 \pm 51 \mu \mathrm{m}$ for PCL. For scaffold porosity, we found 92.38 plus $0.20 \%$ for PHBV, 93.17 plus $0.34 \%$ for $75: 25$ blend and 93.68 plus $0.87 \%$ for PCL. For the 50:50 blend we did not determine the porosity estimate, as we found that the sample was not uniform and therefore the error would be very large.

Several problems with the production of the 50/50 blends were encountered, when the formation of the membrane occurred, they were immiscible, which resulted in phase separation and consequently, very irregular aspect, susceptible to cracks and fractures during handing (data not shown).

\subsection{MTT assay}

After $24 \mathrm{~h}$ of incubation (Figure 3), the results of the MTT assay obtained for the samples studied were lower than those observed for the positive control and higher than those found for the negative control, except for the porous 50/50 blend. Good results were obtained for the porous polymers, with all samples showing results similar to that of the positive control. Considering the arrangement of the material, its purpose, the search for bone implants, low resistance of the sample to handling and low initial cellular activity, the utility of the $50 / 50$ began to be questioned.

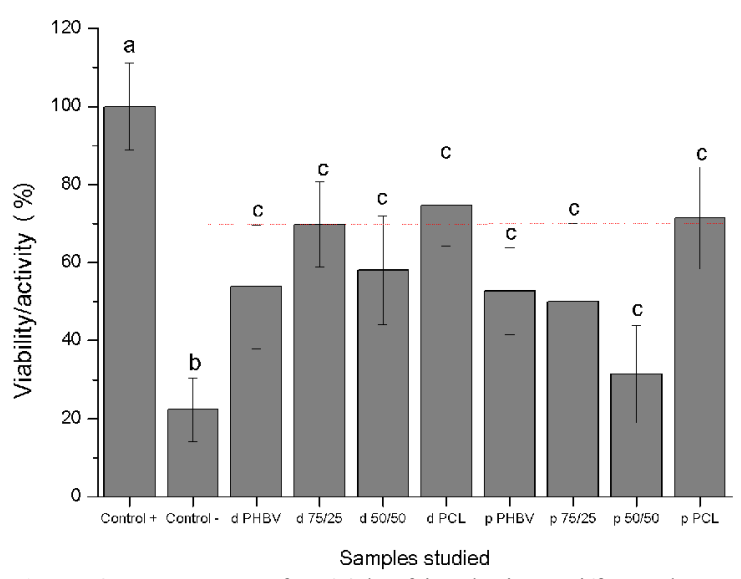

Figure 3. MTT assay after $24 \mathrm{~h}$ of incubation. Different letters indicate significant differences between groups $(\mathrm{p}<0.05)$.

\subsection{Morphological analysis}

The morphology of Vero cells in contact with extracts of the polymers is shown in Figure 4. No variations were observed between dense or porous samples and the control (data do not shown). We therefore chose to report the data together. The cells were evenly distributed over the plate and contained a round or slightly oval nucleus, decondensed chromatin and a visible nucleolus. The level of confluence of cells grown on the plates was greater than that of cells grown on the substrates as expected. There were no signs suggesting toxicity of the extract in any of the samples studied.

The light microscopy results of cells grown on the dense and porous polymers are illustrated in Figure 4. Crystal violet staining showed that the cells proliferated and occupied large part of the surface of the materials. Cells almost reaching confluence were observed in some areas, while there was still space for cell growth in others. Cells with decondensed chromatin were observed, but the nucleoli were less evident. In the case of the dense polymers, a finding that called attention was the smaller number of cells on the 50/50 blends compared to the other samples. 


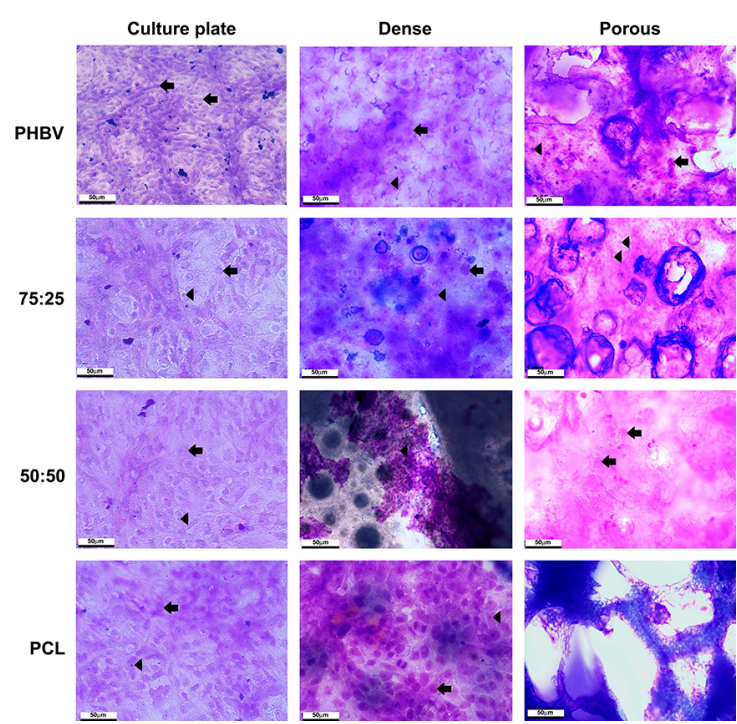

Figure 4. Morphological analysis of Vero cells cultured with the extracts of the samples and on the dense and porous polymers for 5 days. Decondensed chromatin (arrow) and a visible nucleolus (arrowhead) could be seen on the imagens. Crystal violet dye was used. Scale bar $=50 \mu \mathrm{m}$ (for all other images).

It was much more laborious to find fields with cells growing on these polymers (Figure 4). The same was observed for the porous samples (Figure 4). These data corroborate the findings of the MTT assay that suggested difficulties of cell growth on the 50/50 blends, although this effect was not observed for the extracts of these samples.

\subsection{Cytochemical analysis under direct contact conditions}

Cytochemical analysis is used to detect elements in cells that provide information about cellular activity on biomaterials. The cytochemical data are shown in Figure 5 (cells cultured on the dense polymers) and Figure 6 (cells cultured on the porous polymers).

$\mathrm{PH}$ selectively stains collagen ${ }^{19-21}$. It was found no evident signs of the presence of collagen by this technique in dense samples. More marked staining was observed in porous samples.

$\mathrm{XP}$ is an acidophilic dye that stains total proteins at $\mathrm{pH} 2.5^{20,22}$. It was found strongly stained cells, especially on PCL and the 75/25 blend, indicating large amounts of protein in the cells.

Silver staining is used for the identification of reticular fibers ${ }^{19,20}$. Deposition of precipitated material was observed in some samples, with greater deposition on PHBV. The formation of reticular fibers was only suggested for dense PHBV (Figure 5).

Verhoeff's stain is commonly used for the demonstration of elastic fibers ${ }^{19,20}$. It was found no signs of deposition of this material on any of the substrates, either dense or porous samples.
TB is a basic dye that is used to identify DNA, RNA and GAGs at $\mathrm{pH} 4.0{ }^{20-22}$. In general, cells that grew on dense polymers stained with TB at $\mathrm{pH} 4.0$ exhibited metachromatic cytoplasm. The nuclei were also metachromatic, indicating the deposition of a large number of radicals stained by TB. With respect to the porous polymers, since these materials are thicker, the images obtained did not allow a clear analysis as that done for the dense materials. However, layers of cells with metachromatic cytoplasm were found scattered on the samples (Figures 5 and 6). At pH 2.5, TB is used to identify only GAGs ${ }^{20-22}$. Only residual staining was observed in all samples, indicating the absence of GAGs. Taken together, these results show that, at $\mathrm{pH} 4.0$, TB stained nucleic acids. In the cytoplasm, this staining indicates the presence of rRNA in the abundant rough endoplasmic reticulum, corroborating the data obtained by the XP technique.

PAS is used to demonstrate the presence of neutral sugars and of the glycan portion of glycoproteins ${ }^{19,20}$. In dense samples, higher staining was only observed on PHBV (Figure 5). In porous samples, this staining was absent on the 50/50 blend (Figure 6). In general, more intense staining was detected in cells grown on the porous scaffold.

It was found again a smaller number of cells on the $50 / 50$ blends. Fields of semiconfluent cells grown on this blend were less frequent.

\section{Discussion}

The morphological characteristics of the polymers are compatible with the findings of previous studies ${ }^{9}$. With respect to the porous polymers tested in this study, the SEM images showed an irregular surface with pores of variable size that were well-distributed across the sample. In addition, there were no areas without pores, an important feature for cell culture ${ }^{23}$. The pore measures of pure PCL agree with those recommended, with a pore size around 200-300 $\mu \mathrm{m}$ for bone tissue ${ }^{14,24}$.

The porosity of pure PHBV porous membrane was not evident under the stereoscope, probably because it was one of the thickest samples obtained. The thickness of dense membranes was found to be much lower than that of porous membranes, which was already expected because of the apparent volume increase resulting from the presence of pores.

Regarding cell viability, in tissue engineering, adhesion is the first step in the interaction between the cell and scaffold and this step influences the capacity of cells to differentiate, promoting tissue regeneration ${ }^{2}$. The results of the MTT assay demonstrated good initial cell adhesion to the dense and porous materials after $24 \mathrm{~h}$ of incubation, except for the porous 50/50 blend. Significantly superior results were obtained for the remaining samples when compared to the negative control. In studies using PLLA/PHBV blends (60/40 and 50/50), better cell adhesion was found for the blends than for the pure polymers ${ }^{10}$, which was not observed in the present study. 


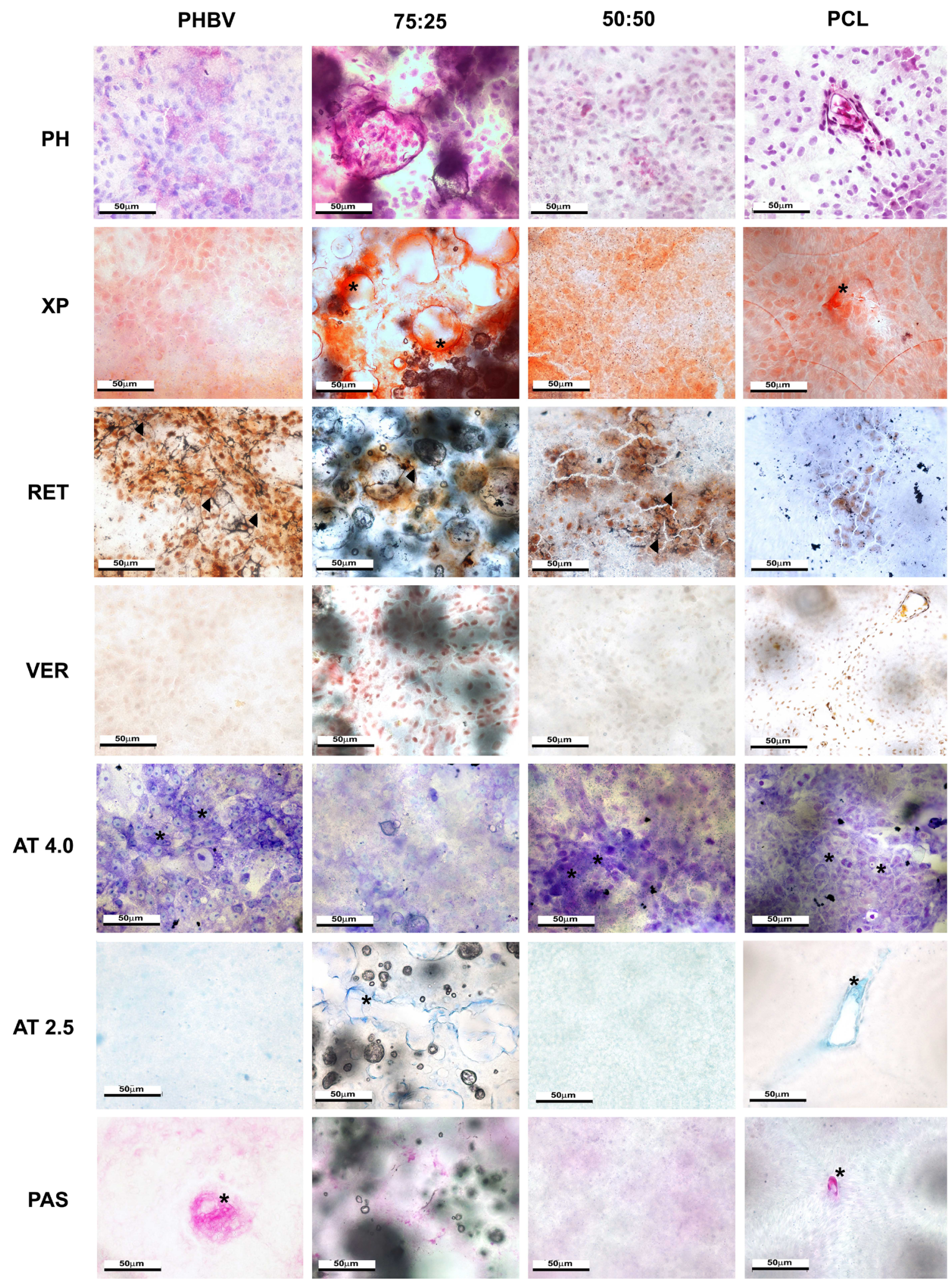

Figure 5. Cytochemical analysis of Vero cells cultured on the dense polymers for 5 days. At the top of the image are the materials used (PHBV, 75:25, 50:50 and PCL). On the side of the figure the cytochemical method used (PH, XP, RET, VER, AT pH 4.0, AT pH 2.5 and PAS). Region with more intense color or reaction indicated by *. Fiber presence indicated by arrowhead. Scale bar $=50 \mu \mathrm{m}$. 


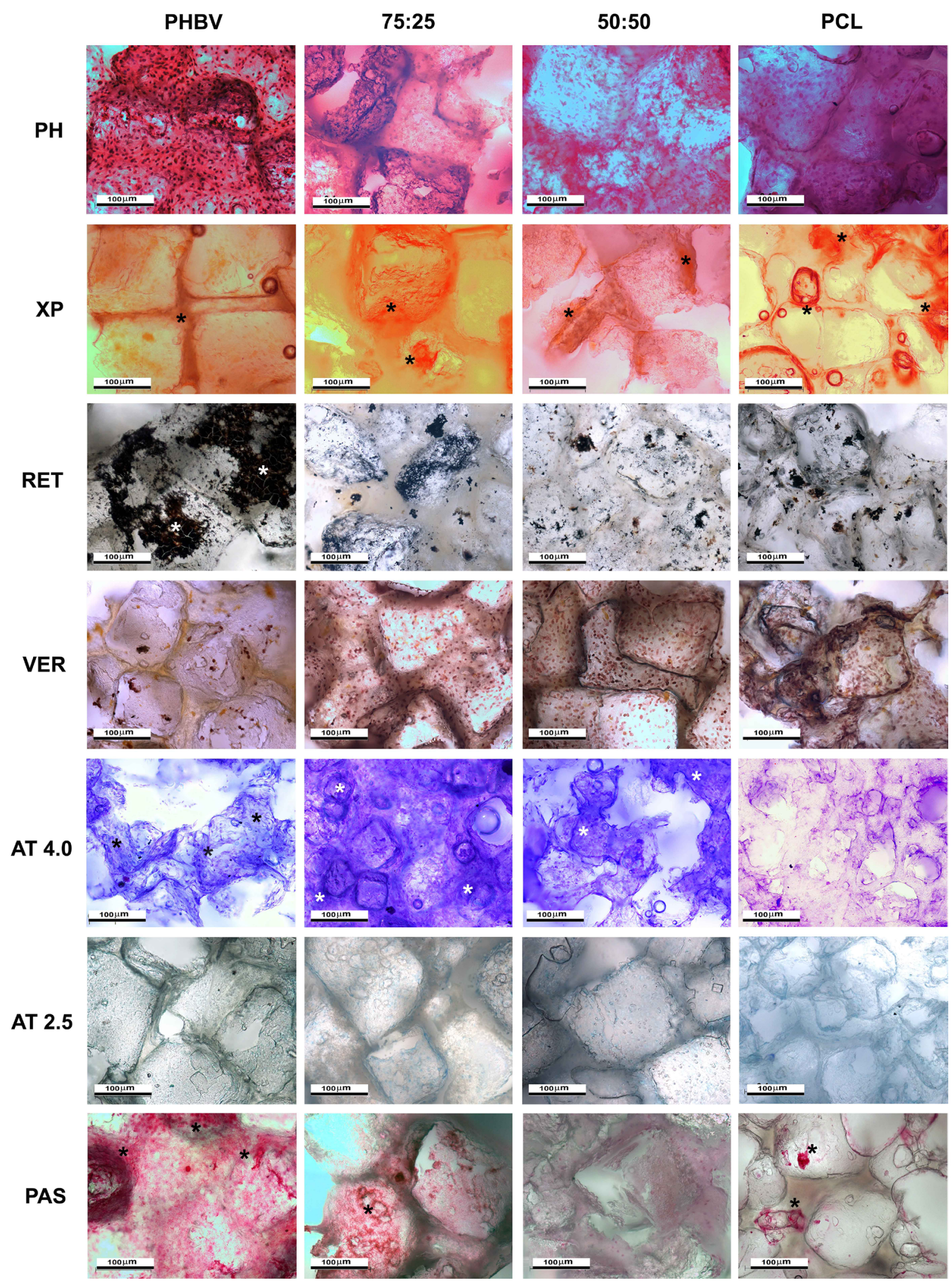

Figure 6. Cytochemical analysis of Vero cells cultured on the porous polymers for 5 days. At the top of the image are the materials used (PHBV, 75:25, 50:50 and PCL). On the side of the figure the cytochemical method used (PH, XP, RET, VER, AT pH 4.0, AT pH 2.5 and PAS). Region with more intense color or reaction indicated by *. Fibers were not observed. Scale bar $=100 \mu \mathrm{m}$. 
The pure polymers, especially PCL, showed as good cell adhesion as the blends. On the other hand, it is possible to stimulate cell adhesion to PHBV by means of modifications in its surface ${ }^{25}$. An important point, although MTT assay has shown a low cellular activity in most samples, it was observed cells forming a semiconfluent layer on polymers in the $120 \mathrm{~h}$ tests, such as morphology and cytochemistry assays. This indicates that the materials are non-toxic. If there were toxicity, cell growth would not be observed. Thus, the data was interpreted as an initial difficulty of interaction between cells and polymers. In anchorage-dependent cells, this difficulty may be reflected in cellular activity.

The surface area of porous material is greater than that of dense material, increasing the area to be filled with cells within the same time interval. For this reason, the cells possibly exhibited better adhesion and proliferation on the dense samples. Low initial cellular activity was observed for the porous 50/50 blend compared to the other materials. Although the cells were able to proliferate on these samples, it was found a smaller number of cells after $120 \mathrm{~h}$ of incubation. Fairly flat cells with decondensed chromatin and a clearly visible nucleolus were observed on all samples.

Cytochemical analysis using PH showed more intense staining in cells cultured on the porous polymers. Staining with XP revealed large amounts of total proteins in cells cultured on the dense and porous samples. No variations were observed between the different polymers. Silver staining showed the presence of some fibrillar material on the dense samples. In the porous materials, punctate staining was observed in some areas. There were no signs of production of elastic fibers in any of the samples studied. Staining with TB detected highly metachromatic cells on all samples, indicating the abundant presence of nucleic acids. Finally, PAS staining was more intense on porous polymers, except for the 50/50 blend. Taken together, the data indicate a good cytochemical performance of the cells on the polymers. Comparative data were recently presented on fibrous PCL materials ${ }^{26}$ or PLLA/ PCL blends ${ }^{27}$. However, the 50:50 blend seemed to show inferior results to the other polymers studied.

Although the porous materials contain a larger area for cell growth and a proportionally smaller number of cells, the cytochemical data indicate high cellular activity on these scaffolds, which exhibited a higher intensity of staining with PH and PAS. When stained with XP and TB, porous samples were comparable to the dense materials, suggesting the use of these samples for tissue engineering. Porous samples are best suited for applications in tissue engineering ${ }^{28}$ because of their larger surface area, providing ample space for cell and vascular invasion ${ }^{14,24}$. In the porous samples, the cells spread across the surface and into the pores. This finding suggests that cells are able to proliferate on this irregular material, migrating to pores and forming a three-dimensional arrangement ${ }^{29}$.

\section{Conclusions}

Taken together, the results of the analyses using Vero cells showed that, except for the 50/50 blends, the scaffolds were capable for maintaining cell growth in vitro. We found no toxicity and the cells showed good function on the materials. Low initial cellular activity was observed for the $50 / 50$ blends. Despite recovery of part of the culture, it was always observed a smaller number of cells on these samples and often-weaker cytochemical staining. For this reason and due to the low resistance of the material to handling, the $50 / 50$ blend should be excluded from mesenchymal stem cell assays and future implantation into animals.

\section{Acknowledgements}

We thank INCT-Biofabris and Fapesp (grant 2015/24374-2) for financial support. We thank also Multiuser Experimental Center (CEM) of UFABC and ProPG/UFABC for the fellowship granted to Amália Baptista-Perianes.

\section{References}

1. Madl CM, Heilshorn SC, Blau HM. Bioengineering strategies to accelerate stem cell therapeutics. Nature. 2018;557(7705):335-342.

2. Santos Junior AR, Zavaglia CAC. Tissue Engineering Concepts. In: Hashmi S, editor. Reference Module in Materials Science and Materials Engineering. Oxford: Elsevier; 2016. p. 1-5.

3. Barbanti SH, Santos Junior AR, Zavaglia CA, Duek EA. Poly( $\mathcal{E}$ caprolactone) and poly(D,L-lactic acid-co-glycolic acid) scaffolds used in bone tissue engineering prepared by melt compression particulate leaching method. Journal of Mater Science. Materials in Medicine. 2011;22(10):2377-85.

4. Sultana N, Wang M. PHBV/PLLA-based composite scaffolds fabricated using an emulsion freezing/freeze-drying technique for bone tissue engineering: surface modification and in vitro biological evaluation. Biofabrication. 2012;4(1):015003.

5. Wang L, Du J, Cao D, Wang Y. Recent advances and the application of poly(3-hydroxybutyrate-co-3-hydroxyvalerate) as tissue engineering materials. Journal of Macromolecular Science: Part A. 2013;50(8):885-893.

6. Casarin SA, Malmonge SM, Kobayashi M, Agnelli M, Augusto J. Study on in vitro degradation of bioabsorbable polymers poly(hydroxybutyrate-co-valerate) - (PHBV) and poly(caprolactone) - (PCL). Journal of Biomaterials and Nanobiotechnology. 2011;2(3):207-215.

7. Malikmammadov E, Tanir TE, Kiziltay A, Hasirci V, Hasirci N. PCL and PCL-based materials in biomedical applications. Journal of Biomaterials Science. Polymer Edition. 2018;29(79):863-893.

8. Siddiqui N, Asawa S, Birru B, Baadhe R, Rao S. PCL-based composite scaffold matrices for tissue engineering applications. Molecular Biotechnology. 2018;60(7):506-532. 
9. Simbara MMO, Ferreira FA, Silva ABM, Santos Junior. AR, Malmonge SM. Comparative study of dense porous and fibrous poly(hydroxybutyrate-co-valerate) (PHBV) and poly(ecaprolactone) (PCL) scaffolds. Annals of VIII Congreso Latinoamericano de Órganos Artíficiales, Biomateriales e Ingeniería de Tejidos; 2014 aug. 20-23; Rosario, Argentina. Rosario: Book of Annals COLAOB; 2014. p.275.

10. Santos Junior AR, Ferreira BMP, Duek EAR, Dolder H, Wada RS, Wada MLF. Differentiation pattern of Vero cells cultured on poly(L-lactic acid)/poly(hydroxybutyrate-co-hydroxyvalerate) blends. Artificial Organs. 2004;28(4):381-89.

11. Santos Junior AR, Ferreira BMP, Duek EAR, Dolder H, Wada MLF. Use of blends of bioabsorbable poly(L-lactic acid)/ poly(hydroxybutyrate-co-hydroxyvalerate) as surfaces for Vero cell culture. Brazilian Journal of Medical and Biological Research. 2005;38(11):1623-1632.

12. Rodrigues AA, Batista NA, Belangero WD, Casarin AS, Agnelli JAM, Santos Junior AR. Diferenciação osteogênica de células-tronco mesenquimais de rato cultivadas em arcabouços de poli (hidroxibutirato-co-hidroxivalerato), poli (caprolactona) e suas blendas. Annals of the $7^{\text {th }}$ Latin American Congress of Artificial Organs and Biomaterials; 2012 aug. 22-25; Natal, Brazil. Natal (RN): Book of Annals COLAOB; 2012. p. 857-70.

13. Zavaglia CAC, Silva MHP. Biomaterials. In: Hashmi S, editor. Reference Module in Materials Science and Materials Engineering. Oxford: Elsevier; 2016. p. 590.

14. Oryan A, Alidadi S, Moshiri A, Maffulli N. Bone regenerative medicine: classic options, novel strategies, and future directions. Journal of Orthopaedic Surgery and Research. 2014;9(1):18.

15. American Society for Testing Materials (ASTM). F813-83(1996) e1 - Standard practice for direct contact cell culture evaluation of materials for medical devices. West Conshohocken, PA: ASTM International; 2001.

16. Standards Catalogue (ICS). ISO 10993-5:2009 - Biological evaluation of medical devices. Part 5: Tests for in vitro cytotoxicity. Geneva: ICS; 2009.

17. LeBlon CE, Pai R, Fodor CR, Golding AS, Coulter JP, Jedlicka $\mathrm{SS}$. In vitro comparative biodegradation analysis of salt-leached porous polymer scaffolds. Journal of Applied Polymer Science. 2013;128(5):2701-2712.
18. Kirkpatrick CJ. Biological testing of materials and medical devices - A critical view of current and proposed methodologies for biocompatibility testing: cytotoxicity in vitro. Regulatory Affairs. 1992;4(1):13-32.

19. Lison L. Histochemie et Cytochemie Animales: Principles et Methodes. Paris: Gauthier Villars; 1960.

20. Toboga SR, Vilamaior PSL. Citoquímica. In: Carvalho HF, Recco-Pimentel SM, editors. A Célula. $3^{\text {a }}$ ed. São Paulo (SP): Manole; 2013. p. 60-68.

21. Módis L. Organization of the Extracellular Matrix: A Polarization Microscopy Approach. Boca Raton: CRC Press; 1991.

22. Mello MLS. Cytochemistry of DNA, RNA and nuclear proteins. Brazilian Journal of Genetics. 1997;20(2):257-264.

23. Motta AC, Fedrizzi VM, Barbo MLP, Duek EAR. In vitro and in vivo studies on devices of poly(l-co-d,1 lactic acid)-co-TMC for bone repair. Polymer Bulletin. 2018;75(4):4515-4529.

24. Karageorgiou V, Kaplan D. Porosity of 3D biomaterial scaffolds and osteogenesis. Biomaterials. 2005;26(27):5474-91.

25. Lucchesi C, Ferreira BMP, Duek EAR, Santos Junior AR, Joazeiro PP. Increased response of Vero cells to PHBV matrices treated by plasma. Journal of Materials Science. Materials in Medicine. 2008;19(2):635-643.

26. Simbara MMO, Santos Junior AR, Andrade AJP, Malmonge SM. Comparative study of aligned and non-aligned poly $(\varepsilon-$ caprolactone) (PCL) fibrous scaffolds prepared by solution blow spinning. Journal of Biomedical Materials Research: Part B. 2019;107(5):1462-1470.

27. Vida TA, Motta AC, Santos Junior AR, Cardoso GBC, Brito CC, Zavaglia CAC. Fibrous PCL/PLLA scaffolds obtained by rotary jet spinning and electrospinning. Materials Research. 2017;20(Suppl 2):910-916.

28. Cunha MR, Alves MC, Calegari ARA, Iatecola A, Galdeano EA, Galdeano TL, et al. In vivo study of the osteoregenerative potential of polymer membranes consisting of chitosan and carbon nanotubes. Materials Research. 2017;20(3):819- 825.

29. Mendes Junior D, Domingues JA, Hausen MA, Cattani SMM, Aragones A, Oliveira ALR, et al. Study of mesenchymal stem cells cultured on a poly(lactic-co-glycolic acid) scaffold containing simvastatin for bone healing. Journal of Applied Biomaterials and Functional Materials. 2017;15(2):e133-e141. 